\title{
Flow-dependent and dynamical systems analyses of predictability of the Pacific-North American summertime circulation
}

\author{
Ebrahim Nabizadeh, Sandro W. Lubis, and Pedram Hassanzadeh * \\ Rice University, Houston, Texas, USA
}

\begin{abstract}
Forecast skills of numerical weather prediction (NWP) models and intrinsic predictability can be flow-dependent, e.g., different among weather regimes. Here, we have examined the predictability of distinct Pacific-North American weather regimes in June-September. Four weather regimes are identified using a self-organizing map analysis of daily 500-hPa geopotential height anomalies, and are shown to have distinct and coherent links to near-surface temperature and precipitation anomalies over the North American continent. The 4 to 14-day forecast skills of these 4 regimes are quantified for the ECMWF and the NCEP models (from the TIGGE project) and the Global Ensemble Forecast System (GEFS). Based on anomaly correlation coefficient, persistence, and transition frequency, the highest forecast skills are consistently found for regime 3 (Arctic high). In general, the least skillful forecasts are for regime 1 (Pacific trough). The instantaneous local dimension and persistence of each regime are computed using a dynamical systems-based analysis. The local dimension and persistence are indicators of intrinsic predictability. This analysis robustly shows that regime 3 has the highest intrinsic predictability. The analysis also suggests that overall, regime 1 has the lowest intrinsic predictability. These findings are consistent with the high (low) forecast skills of NWP models for regime 3 (regime 1). Weather regime 1 is associated with above-normal temperature and precipitation anomalies over western North America and around the Gulf of Mexico region, indicating potentially important implications for the poor predictability of this regime. The dynamical systems analysis suggests that better estimates of initial conditions might improve the forecasts of this regime.
\end{abstract}

\section{Introduction}

Because of the chaotic nature of the midlatitude largescale circulation, the forecast skills of numerical weather prediction (NWP) models can be flow-dependent. As a result, the high (low) forecast skills for a flow pattern might be due to its high (low) intrinsic predictability (Lorenz 1996; Ferranti et al. 2015; Faranda et al. 2017b). Low forecast skills can also be due to model errors (e.g., incorrect representation of physical processes, inadequate numerical resolution), which can disproportionally affect some flow patterns more (Dawson et al. 2012; Weisheimer et al. 2019; Strommen and Palmer 2019; Hannachi and Iqbal 2019). In recent years, there has been a growing interest in studying the flow-dependent predictability of the midlatitude circulation using a few distinct patterns obtained from clustering fields such as daily geopotential height at $500 \mathrm{hPa}$ (Z500 hereafter). These clusters often represent recurrent, persistent flow anomalies that are thought to be connected to preferred regions in the circulation's phase-space and referred to as weather regimes (e.g., Mo and Ghil 1988; Vautard 1990; Michelangeli et al. 1995; Robertson and Ghil 1999; Casola and Wallace 2007; Cassou 2008; Ferranti et al. 2015). Furthermore, various studies have established connections between these distinct weather regimes and specific surface weather and extreme

\footnotetext{
*Corresponding author: Pedram Hassanzadeh, pedram@ rice.edu
}

events, indicating the benefits of studying predictability in the context of a few weather regimes (e.g., Yiou et al. 2008; Robertson et al. 2015; Vigaud et al. 2017, 2019; Amini and Straus 2019; van der Wiel et al. 2019; Pasquier et al. 2019; Chattopadhyay et al. 2020b; Gibson et al. 2020; Hassanzadeh et al. 2020; Robertson et al. 2020).

The North Atlantic weather regimes have been extensively studied in the past (Vautard 1990; Michelangeli et al. 1995; Yiou et al. 2008; Cassou 2008; Woollings et al. 2010; Michel and Rivière 2011; Ferranti et al. 2015; Matsueda and Palmer 2018; Ferranti et al. 2018; Falkena et al. 2020; Fabiano et al. 2021). In winters, most studies have identified 4 distinct regimes in this sector: the positive and negative phases of the North Atlantic Oscillation (NAO), Atlantic Ridge, and Scandinavian Blocking. The flow is fairly zonal in the two phases of NAO (southward shifted in the negative phase), while the flow is non-zonal (blocked) over the North Atlantic Ocean and Northern Europe in the Atlantic Ridge and Scandinavian Blocking regimes, respectively. Using daily Z500 from the 2007-2012 European Centre for Medium-range Weather Forecast (ECMWF) operational ensemble forecasts, Ferranti et al. (2015) examined the 5 to 15-day forecast skills in the context of these 4 weather regimes. Overall, based on anomaly correlation coefficient (ACC) values, they found higher forecast skills for both phases of NAO compared to the Blocking and Atlantic Ridge regimes. More specif- 
ically, their analysis showed that forecasts started during the negative phase of NAO have the highest skill beyond 10 days, and that the least skillful forecasts are associated with missing the transition to the blocked flows. They also found that forecasts underestimate and overestimate the persistence of blocked and zonal flows, respectively.

More recently, Faranda et al. (2017b) have provided an explanation for the poor predictability of blocked flows reported by Ferranti et al. (2015). Using a novel dynamical systems-based analysis (Lucarini et al. 2016), they computed, for each weather regime, the local dimension $d$ and persistence $\theta^{-1}$, which are indicators of the regime's intrinsic predictability. $d$ is the chaotic attractor's local (in phase-space) dimension and quantifies the complexity of a given state-in this case, a weather regime (Freitas et al. 2010; Lucarini et al. 2012; Faranda et al. 2017b). $\theta^{-1}$ measures the persistence (i.e., stability) of trajectories around a given state (Freitas et al. 2010; Lucarini et al. 2012). Faranda et al. (2017b) found that blocked flows have higher dimensions and are less stable (i.e., higher $d$ and $\theta$ values) compared to the zonal flows, indicating lower intrinsic predictability for the Blocking and Atlantic Ridge regimes. These findings suggested that the low predictability of blocked flows reported by Ferranti et al. (2015) was, at least partially, due to the blocked flows' low intrinsic predictability. Together, these results show the benefits of combining the flow-dependent and dynamical systems analyses in examining the large-scale circulation predictability. It should be mentioned that this dynamical systems-based analysis has also been used in a number of other recent papers to study various aspects of the midlatitude circulation and climate system (e.g., Messori et al. 2017; Faranda et al. 2017a; Robin et al. 2017; Rodrigues et al. 2018; Buschow and Friederichs 2018; Messori et al. 2018; Faranda et al. 2019a,b; Hochman et al. 2019; Brunetti et al. 2019; De Luca et al. 2020).

Unlike the North Atlantic-European sector, the weather regimes of North Pacific-North America have received much less attention, and mostly studied in wintertimes (Robertson and Ghil 1999; Straus and Molteni 2004; Straus et al. 2007; Casola and Wallace 2007; Stan and Straus 2007; Riddle et al. 2013; Robertson et al. 2015, 2020; Fabiano et al. 2021). Using daily Z500 from the 1995âĂŞ2014 ECMWF 11-member reforecasts in the S2S database (Vitart et al. 2017), Vigaud et al. (2018) studied the predictability of the wintertime weather regimes over North America for up to 4-weeks. Based on ACC values, they found the highest skill for forecasts started in the regime resembling the negative phase of the Pacific-North American teleconnection pattern (PNA).

In summers of North Pacific-North America, a number of studies have identified specific circulation patterns associated with significant impacts on surface weather and extreme events, such as heat waves and droughts (e.g., Chang and Wallace 1987; Vavrus et al. 2017; Zheng and
Wang 2019). However, to the best of our knowledge, there has not been any work focused on the flow-dependent and dynamical systems analyses of the predictability of the North Pacific-North American summertime circulation at the medium-range timescales.

In this paper, we present the results of such investigation. We will first identify weather regimes over the PacificNorth American sector during the extended summer season (June-September) using self-organizing maps (SOMs) for clustering analysis. To show the impact of these weather regimes, we will demonstrate that distinct and coherent patterns in surface temperature and precipitation over the North American continent are associated with each regime. We will also show connections between each regime and specific phases of the Madden-Julian Oscillation (MJO). Then, using forecasts from 3 NWP models, we will quantify the 4 to 14 -day predictability of each regime. Finally, we will compare the $d$ and $\theta$ of these regimes and examine connections between the intrinsic predictability of weather regimes and the forecast skills in the NWP models.

The remainder of this paper is structured as follows. Data and methods are described in Section 2. In Section 3 , the identified weather regimes and their impacts are analyzed. In Section 4, the skills for forecasts initiated in each regime and during regime transitions are quantified followed by the dynamical systems analysis. Final remarks and conclusions are in Section 5.

\section{Data and methods}

\section{a. Reanalysis datasets}

Weather regimes over the North Pacific-North American sector $\left(0-90^{\circ} \mathrm{N}\right.$ and $\left.150^{\circ} \mathrm{E}-60^{\circ} \mathrm{W}\right)$ are examined in the extended summer season (June-September) during 19792018 using daily Z500 patterns. Here we use two different reanalysis datasets: ECMWF's ERA-Interim (Dee et al. 2011) and NCEP-DOE (Kanamitsu et al. 2002). ERAInterim has a spatial resolution of $0.75^{\circ} \times 0.75^{\circ}$ and NCEPDOE has a resolution of $2.5^{\circ} \times 2.5^{\circ}$. Impacts of the identified weather regimes are analyzed using daily 2 -meter air temperature (T2m) and precipitation rate from both reanalysis datasets. Anomalies for these variables are calculated by removing the climatological mean, defined as the 31 day running-mean centered around that calendar date and averaged over all years (Nabizadeh et al. 2019).

\section{b. Numerical weather prediction (NWP) models}

Forecast skills for summertime weather regimes are assessed in three different medium-range NWP models in the 2008-2018 period. Two models are chosen from THORPEX $^{1}$ International Grand Global Ensemble (TIGGE) project (Bougeault et al. 2010). One of the models is from ECMWF with 51 members and the other one is from

${ }^{1}$ The Observing system Research and Predictability Experiment. 
the National Centers for Environmental Prediction (NCEP) with 21 members. The ECMWF model has a horizontal resolution of $0.28^{\circ} \times 0.28^{\circ}$ up to day 10 of the forecast; afterwards, the resolution is reduced to $0.56^{\circ} \times 0.56^{\circ}$. The NCEP-TIGGE model has a resolution of $0.7^{\circ} \times 0.7^{\circ}$ up to day 8 , then the resolution is reduced to $0.95^{\circ} \times 0.95^{\circ}$. We have chosen these two models because they, in particular the one from ECMWF, have been shown to provide better predictions compared to the other models in the TIGGE project (Swinbank et al. 2016). The third NWP model used in this study is the 2nd generation NOAA Global Ensemble Forecast System (GEFS; Hamill et al. 2013). The GEFS 11-member ensemble reforecast is produced by NCEP using the same resolution as that of the TIGGE-NCEP model. In these reforecasts, the diagnosed errors from the past forecasts have been corrected (Hamill et al. 2013). These three models are among the NWP models used by Matsueda and Palmer (2018) to study the predictability of weather regimes over the North Atlantic sector and are freely available for public access (see the Data availability statement).

\section{c. Clustering analysis}

To identify summertime weather regimes in the reanalysis data, we have applied SOM clustering analysis (Kohonen 2012) to the daily Z500 anomalies. SOM is an artificial neural network that has been extensively used to classify climate data (e.g., Johnson et al. 2008; Lee and Feldstein 2013; Horton et al. 2015; Singh et al. 2016; Gervais et al. 2020; Hassanzadeh et al. 2020). It should be mentioned that there are a variety of methods that have been used for clustering weather patterns and it is not clear if any is better than the rest (e.g., see Mo and Ghil 1988; Ghil and Robertson 2002; Robertson and Mechoso 2003; Ashok et al. 2017; Sahai et al. 2017; Straus 2018; Chattopadhyay et al. 2020a, and references therein). At least in one recent study, Bao and Wallace (2015) concluded that the flow regimes derived from SOM analysis are more distinctive and more robust than those obtained using Ward's method, which is a type of hierarchical clustering method.

Here, we have clustered the data into four distinguishable regimes using a map of 4 by 1 nodes. The results remain the same with different map configurations such as 1 by 4 and 2 by 2 , where the spatial correlations between two similar cluster centers in different map configurations are almost one. Our extensive exploration suggests that the optimal number of clusters is four as the cluster centers are distinguishable and physically meaningful (see Section 3); repetitive patterns appear if we cluster the anomalies into 5 regimes.

\section{d. Predictability metrics}

Following Ferranti et al. (2015) and other studies, to measure and compare the predictability of weather regimes in the NWP models, we compute ACC, which is defined as

$$
A C C=\frac{\overline{\left(Z_{F}-C\right) \times\left(Z_{R}-C\right)}}{\sqrt{\overline{\left(Z_{F}-C\right)^{2}} \times \overline{\left(Z_{R}-C\right)^{2}}}},
$$

for a given day. Then the ACC values of days corresponding to each weather regime are averaged to compute each regime's ACC. Here, $Z_{F}$ and $Z_{R}$ are the full-field $Z 500$ patterns from forecast and from reanalysis, respectively; $C$ is the climatological mean of Z500. Overbars indicate domain averaging.

Follwoing Ferranti et al. (2015), to determine which weather regime a forecasted Z500 pattern belongs to, we compute the root-mean-square error (RMSE) between the forecasted $Z 500$ anomaly and the cluster center $Z_{c}$ of each weather regime as

$$
R M S E=\sqrt{\left[\overline{\left.\left(Z_{F}-C\right)-Z_{C}\right]^{2}}\right.} .
$$

The minimum RMSE value indicates the regime that the predicted anomaly belongs to.

\section{e. Dynamical systems analysis: Local dimension and per- sistence}

The instantaneous local dimension $d$ and persistence $\theta^{-1}$ are computed based on daily Z500 over the North Pacific-North American sector. $d$ and $\theta$, which are fully described in Lucarini et al. (2016), measure the intrinsic predictability of a given state, and can be used to quantify the intrinsic predictability of a weather regime. $\theta^{-1}$ measures the residence time of a trajectory within a small radius of a state $\xi(t)$. Looking at the two extrema of $\theta$ : if $\xi(t)$ is a fixed-point, then $\theta(\xi)=0$, while if a trajectory immediately leaves $\xi$, then $\theta(\xi)=1$ (Faranda et al. 2017b). That means states with higher $\theta^{-1}$ are more stable and persistent: trajectories stay longer in the vicinity of these states (Faranda et al. 2016). $d$ measures the number of active degrees of freedom for a state $\xi(t)$ and is the local dimension of the chaotic attractor. In this framework, $0<\theta<1$ and $0<d<\infty$ can be computed (as described below) for each state $\xi(t)$. Note that the more familiar attractor dimension of a system (e.g., 2.06 for Lorenz 63) is the average of all the $d$ values for all states (Faranda et al. 2017b).

Following Messori et al. (2017), each daily Z500 pattern is treated as a point along a single trajectory. To compute the instantaneous dynamical properties of the system, the timeseries of distances between a state of interest $\xi$, a given daily $Z 500$ field, and all other states ( $Z 500$ samples) is calculated along the trajectory. The distance between $\xi$ and daily $Z 500$ at a given time $t$ is computed as

$$
\begin{aligned}
& \operatorname{dist}(Z(t), \xi)= \\
& \sqrt{\left(Z_{1}(t)-\xi_{1}\right)^{2}+\left(Z_{2}(t)-\xi_{2}\right)^{2}+\ldots+\left(Z_{M}(t)-\xi_{M}\right)^{2}} .
\end{aligned}
$$


Here $Z$ represents the $Z 500$ field, and the subscript $i$ indicates the value at grid points $i=1,2, \ldots . M$. The timeseries $\operatorname{dist}(Z(t), \xi)$ is then used to calculate $d$ and $\theta$ for each state $\xi$ (see Appendix A for details). $d$ and $\theta$ are computed for all daily Z500 patterns as $\xi$. Finally, the distributions of $d$ and $\theta$ values for all $\xi$ in each weather regime are computed.

\section{The observed weather regimes and their impacts}

\section{a. Z500 cluster centers}

Figure 1 shows the cluster centers of the identified weather regimes from the ERA-Interim and NCEP reanalysis datasets. The two reanalysis datasets yield very similar patterns and frequencies for the 4 weather regimes. Regime 1 (C1) consists of Z500 anomalies corresponding closely to the Pacific trough followed by a ridge over the North American continent. Regimes 2 (C2) and 3 (C3) consist of meridionally oriented ridge and trough anomalies representing the Arctic low and Arctic high, respectively. These regimes, which resemble Rossby wave trains, are also observed in the winter season (Straus et al. 2007; Vigaud et al. 2018). The last regime (C4) represents Z500 anomalies corresponding to the Alaskan ridge extending to the west coast of North America with weaker amplitudes. Table 1 shows the statistics of regime transitions between two constitutive days. In this table, the highest values are along the diagonal for both reanalysis datasets, showing that these regimes are persistent at the daily time scale.

In the following subsections, we will examine the impact of each regime using composite analysis of corresponding surface temperature and precipitation rate anomalies. We will also look at connections between these weather regimes and MJO.

\section{b. Composited near-surface temperature and precipitation rate anomalies}

Figures 2 and 3 show composites of near-surface temperature and precipitation rate for each weather regime and for both reanalysis datasets, which yield fairly consistent results. Regime $1(\mathrm{C} 1)$ is associated with a dipolar temperature anomaly over the North American continent, with warming over the western and cooling over the eastern parts (Figs. 2a-b). The precipitation rate that corresponds to this regime is anomalously high off the west coast of Canada and over the south-east United States and Gulf of Mexico (Figs. 3a-b). The precipitation rate is below average over most of Canada, which is under the high-pressure anomaly.

The second regime (C2) is associated with a spatially unequal dipolar temperature anomaly. Consistent with the location of the low- and high-pressure anomalies, there is a narrow band of below-average temperature over the west coast of the United States and Canada, and there is a broader above-average temperature anomaly over central and eastern North America (Figs. 2c-d). The precipitation rate associated with this regime is above average over western and central Canada, but below the average over substantial parts of the United States (Figs. 3c-d).

The temperature anomaly corresponding to the third regime (C3) is above average over Alaska, which is under a high-pressure anomaly, and below average over central Canada and the western United States, which are under a low-pressure anomaly (Figs. 2e-f). Rainfall is overall above average over most of Canada and the United States but below average over the south-east United States and Gulf of Mexico (Figs. 3e-f).

The fourth regime (C4) is associated with above-normal temperature over the western United States and belownormal temperature over northern Canada. There is a positive precipitation anomaly over the eastern United States and Canada, and small or negative precipitation anomalies over the rest of the North American continent.

Overall, these results show that the identified summertime weather regimes correspond to distinct and coherent temperature and precipitation rate anomalies over the North American continent.

\section{c. MJO teleconnections}

It is known that the northern hemisphere extratropical circulation can be affected by MJO phases with some time lag (e.g., L'Heureux and Higgins 2008; Johnson and Feldstein 2010; Zhang 2013; Schreck et al. 2013; Lee and Grotjahn 2019). Following previous studies, we select active MJO days when the Real-time Multivariate MJO (RMM) index (Wheeler and Hendon 2004) is greater than or equal to one. Similar to the approach taken previously (e.g., Camargo et al. 2009; Vitart 2009; Kossin et al. 2010; Lee and Grotjahn 2019), we group each two consecutive MJO phases to obtain four phase-pairs: an Indian Ocean phase (phases 2-3), a Maritime Continent phase (phases 4-5), a western North Pacific phase (phases 6-7), and a Western Hemisphere phase (phases 8-1). Lee and Grotjahn (2019) showed that in summers, with a time lag of 4 to 16 days, MJO phase-pairs affect extreme weather events over the western United States.

Figure 4 shows the average frequency of each MJO phase-pair for 4-10 days before each weather regime (the results remain the same if the averaging is done over 4-16 days). We see that $\mathrm{C} 1$ and $\mathrm{C} 4$, which are associated with warming over California (Fig. 2a-b and g-h), are the dominant regimes after phase-pairs 8-1 and 2-3 (Fig. 4). This finding is consistent with that of Lee and Grotjahn (2019), who reported connections between MJO phase-pairs 81 and 2-3 and the California Central Valley heat waves. Regime 2, which is associated with a cooling anomaly over the west coast (Fig. 2c-d), has the highest frequency associated with phase-pair 4-5 (Fig. 4). This is also in agreement with the results of Lee and Grotjahn (2019), 
(a) ERA C1: $26.58 \%$

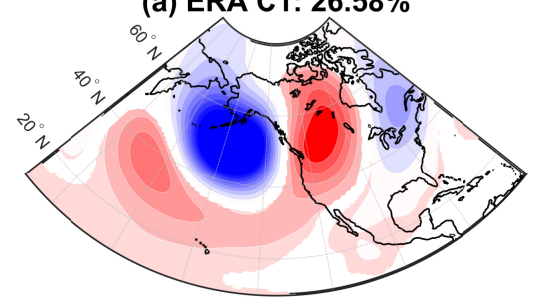

(c) ERA C2: $26.35 \%$

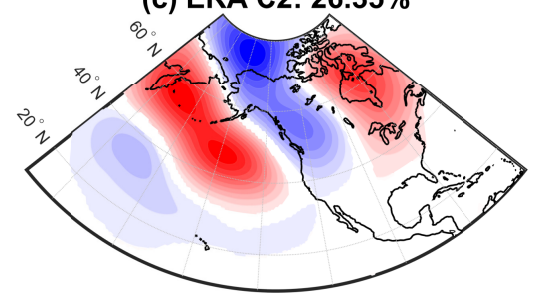

(e) ERA C3: $24.36 \%$

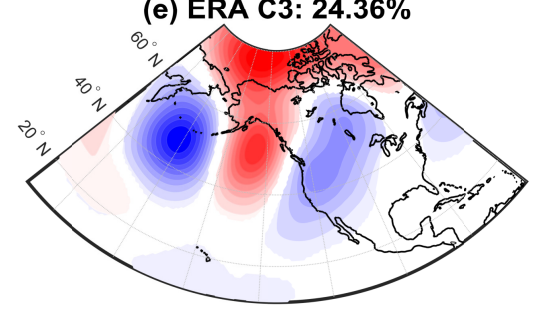

(g) ERA C4: $22.7 \%$

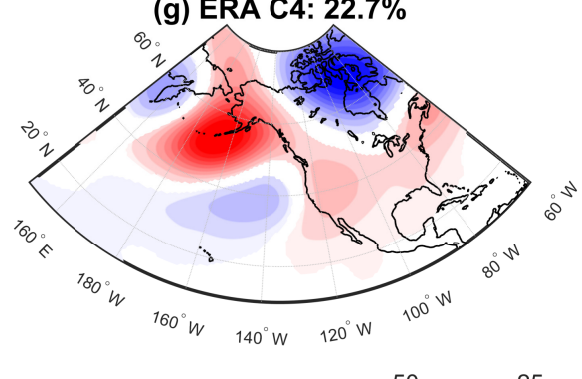

(b) NCEP C1: $27.15 \%$

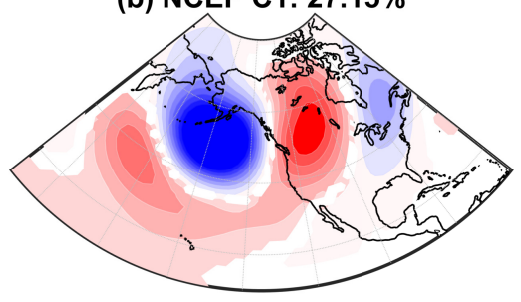

(d) NCEP C2: $25.16 \%$

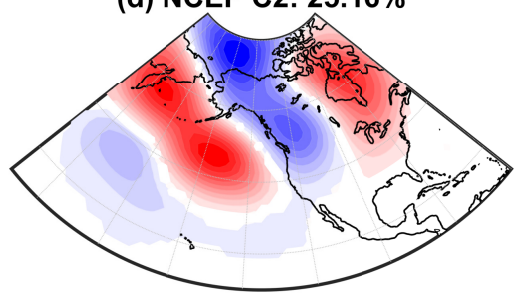

(f) NCEP C3: $24.22 \%$

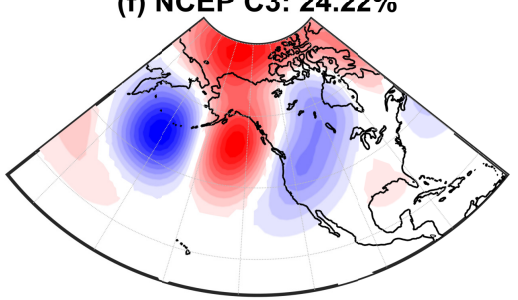

(h) NCEP C4: $23.46 \%$

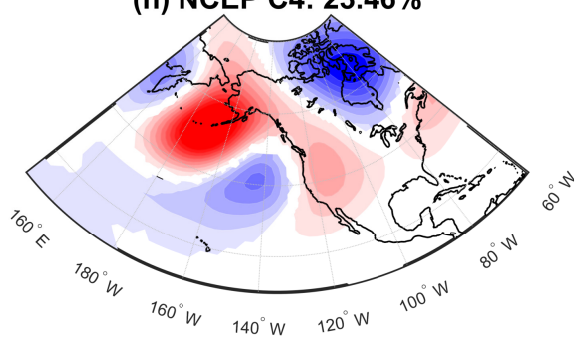

\begin{tabular}{ccccc}
-50 & -25 & 0 & 25 & 50 \\
\hline & & & $m$
\end{tabular}

FIG. 1. Pacific-North American weather regimes, identified during the extended summer season (JJAS) from 1979 to 2018. The left column shows the cluster centers from the ERA-Interim reanalysis (ERA), and the right column shows the cluster centers from the NCEP reanalysis. All shown anomalies are significant at the $95 \%$ level based on a two sided Student's $t$ test. Percentages show the frequency of each cluster.

who have shown that this phase-pair is associated with a cooling anomaly over the United States west coast. They also showed that MJO phase-pair 6-7, which is dominantly related to $\mathrm{C} 3$, is associated with a cooling anomaly over California, though with weaker impacts than phase-pair 45 (this is consistent with the impact of regime 3 in Figs. 2e-f). These connections between the MJO phases and weather regimes are consistent among the two reanalysis datasets (Fig. 4).

We can also examine connections of MJO phases with the weather regimes through the composited precipitation rate anomalies. Regime 1 , which is connected to MJO 
TABLE 1. Transition matrix among the four summertime weather regimes, cluster C1-C4, in the ERA-Intrim and NCEP (in parentheses) reanalysis datasets. Each number indicates the occurrence of a regime in the day following the occurrence of a specific regime.

\begin{tabular}{|c|c|c|c|c|c|}
\hline fromlto & $\mathrm{C} 1$ & $\mathrm{C} 2$ & $\mathrm{C} 3$ & $\mathrm{C} 4$ & Total days \\
\hline \multirow{2}{*}{$\mathrm{C} 1$} & $\begin{array}{c}1045 \\
(1053)\end{array}$ & $\begin{array}{c}91 \\
(90)\end{array}$ & $\begin{array}{c}89 \\
(100)\end{array}$ & $\begin{array}{c}72 \\
(82)\end{array}$ & $\begin{array}{c}1297 \\
(1325)\end{array}$ \\
\hline \multirow{2}{*}{$\mathrm{C} 2$} & $\begin{array}{c}79 \\
(73)\end{array}$ & $\begin{array}{c}1054 \\
(997)\end{array}$ & $\begin{array}{c}61 \\
(55)\end{array}$ & $\begin{array}{c}92 \\
(103)\end{array}$ & $\begin{array}{c}1286 \\
(1228)\end{array}$ \\
\hline \multirow{2}{*}{$\mathrm{C} 3$} & 78 & 56 & 970 & 84 & 1188 \\
& $(80)$ & $(64)$ & $(947)$ & $(90)$ & $(1181)$ \\
\hline \multirow{2}{*}{$\mathrm{C} 4$} & 95 & 85 & 69 & 859 & 1108 \\
& $(119)$ & $(77)$ & $(80)$ & $(869)$ & $(1145)$ \\
\hline
\end{tabular}

phase-pair 8-1 (Fig. 4), leads to significant rainfall over the Gulf of Mexico (Fig. 3c-d). This is consistent with the results of Kossin et al. (2010), who presented evidence for the effect of MJO phase-pair 8-1 on increasing storm formation in the Gulf of Mexico. They also reported a similar contribution from MJO phase-pair 2-3, which is connected to regimes 2 and 4 (Fig. 4). These two regimes are associated with positive precipitation anomalies over the eastern and western parts of the Gulf region, respectively (Fig. 3).

Overall, the results of this section demonstrate that the 4 identified weather regimes have distinct impacts on surface weather and have distinct teleconnections with MJO phasepairs. As discussed above, the regimes' surface weather impacts and MJO phase-pair connections are consistent with previously reported connections between MJO phasepairs and surface weather impacts. Altogether, these results further suggest that studying the predictability of these 4 weather regimes can be useful, as they have robust and distinct impacts. We will also revisit the MJO phase-pair connections later once the intrinsic predictability of these regimes is quantified.

\section{Forecast skills and intrinsic predictability}

\section{a. Forecast skills of NWP models}

In this section, we examine the forecast skills of the 3 NWP models for each weather regime based on ACC values and accuracy of transition frequencies and persistence. It should be noted that the purpose of this analysis is not to compare the performance of these NWP models, rather, the purpose is to compare the predictability of the 4 weather regimes. We conduct this comparison with 3 NWP models in order to examine the robustness of the differences in predictability.

Figure 5 shows the skills of each NWP model for forecasts started in each weather regime based on the ensemblemean ACC values as a function of lead time (4 to 14 days). Overall, the ECMWF-TIGGE model (Fig. 5a), which has the highest resolution and ensemble size, has higher prediction skills compared to the NCEP-TIGGE (Fig. 5b) and GEFS (Fig. 5c) models: the ECMWF-TIGGE forecasts reach ACC of 0.6 at around day 8 , while the NCEP models reach this ACC value at around day 7 or slightly longer. Consistent among these three models, up to day 8 , the highest forecast skills are for regime 3 (C3)-these results are statistically significant. Afterwards, the skills for $\mathrm{C} 3$ and $\mathrm{C} 4$ are comparable and higher than those of $\mathrm{C} 1$ and $\mathrm{C} 2$.

We also assess the NWP models' ability to correctly reproduce the persistence of the regimes and their transitions. Following Ferranti et al. (2015), we start with forecasts initiated in each weather regime and then determine a predicted pattern's weather regime (i.e., cluster index) based on the RMSE values. More specifically, each day's true regime (index) is obtained from the clustering analysis of the ERA-Interim or NCEP reanalysis dataset, and the predicted index is calculated by comparing the NWPs' anomalous Z500 pattern with that of the reanalysis' cluster centers, as discussed in part $d$ of Section 2.

Figure 6a shows the transition frequencies for the forecasts initiated in $\mathrm{C} 1$ in the ECMWF-TIGGE model. The model overestimates the frequency of the days in regime 1 at the beginning (day 3) but underestimates the frequency at longer forecast times; e.g., by $11 \%$ at day 12 . Overall, the model is not able to predict the persistence of regime 1 accurately. Frequencies of transitions to $\mathrm{C} 2$ from $\mathrm{C} 1$ are overestimated after day 6 by an average of $10 \%$, which shows the poor forecasts of transitions to this regime. However, the frequencies of transitions to regimes 3 and 4 are captured accurately by the model even at long lead times. The model overestimates the persistence of regime 2 (Fig. $6 \mathrm{~b}$ ) at all forecast days with an average of $7 \%$ up to day 9 and $13 \%$ at day 12 . The frequencies of transitions to regimes 1 and 4 are underestimated with an average of $4.5 \%$ and $3.5 \%$ at these two forecast lead times, respectively. However, the transitions from regime 2 to regime 3 are accurately captured by the model.

Figure 6c displays the results for the forecasts initiated in $\mathrm{C} 3$. We see that the predicted persistence of regime 3 decreases over forecast time as it is overestimated at day 3 by $7 \%$ but underestimated by $3 \%$ at day 12 (Fig. 6c). Transitions to the other regimes have been captured accurately. Overall, the sum of absolute errors for persistence and transition frequencies ("absolute error" hereafter, see 

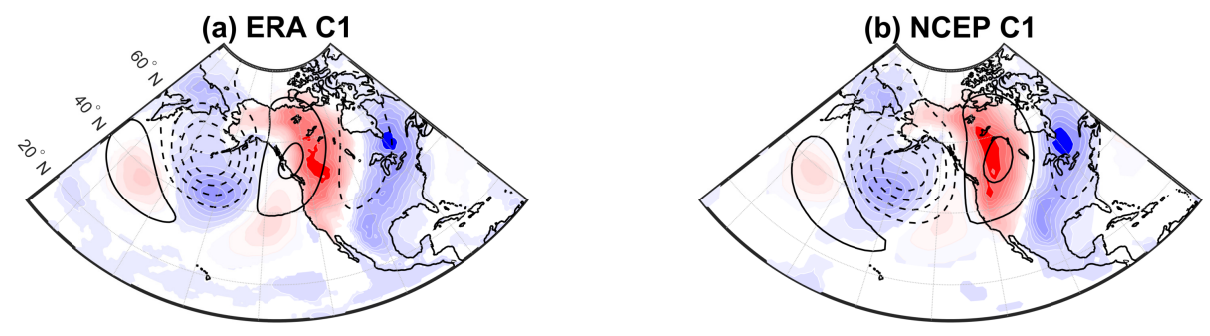

(c) ERA C2
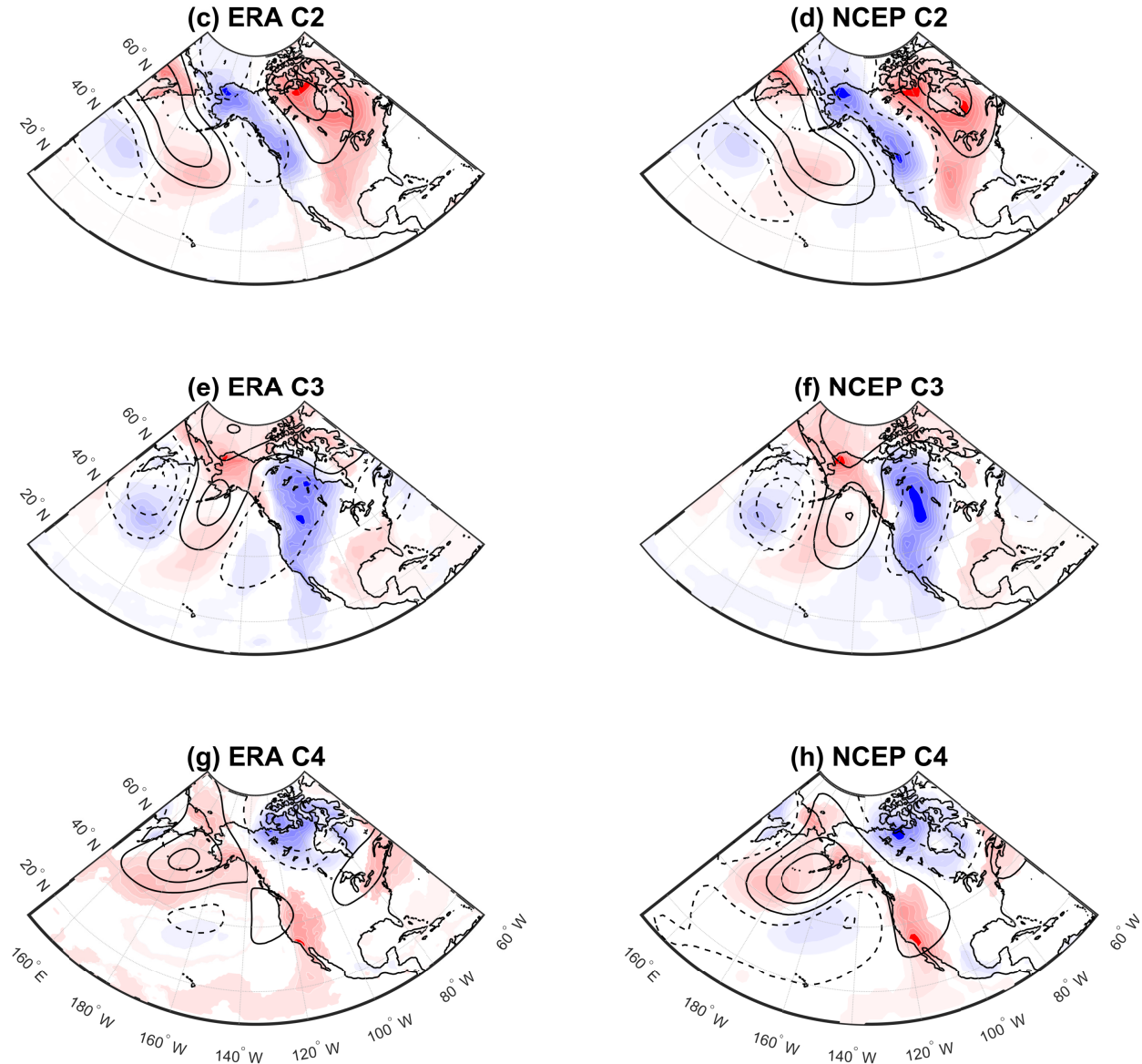

$\begin{array}{lllllll}-3 & -2 & -1 & 0 & 1 & 2 & 3 \\ & & & & & & \end{array}$

FIG. 2. Shading shows composites of near-surface temperature anomalies (T2m, K) associated with each regime. The left column shows the results from the ERA-Interim reanalysis (ERA), and the right column shows the results from the NCEP reanalysis. All shown anomalies are significant at the 95\% level based on a two sided Student's $t$ test. Contourlines are Z500 anomalies of cluster centers (from Fig. 1) with the interval of $20 \mathrm{~m}$.

Appendix B for more details), is the lowest for this regime compared to forecasts initiated in the other regimes (Table 2). This is consistent with the results of Fig. 5 .

Transitions of the forecasts initiated in regime 4 (Fig. 6d) to regime 1 are underestimated; however, transitions to regime 2 have been accurately predicted by the model for short to long forecast lead times. Transitions from $\mathrm{C} 4$ to C3 are overestimated in the model. The persistence of this regime is underestimated in this model. 

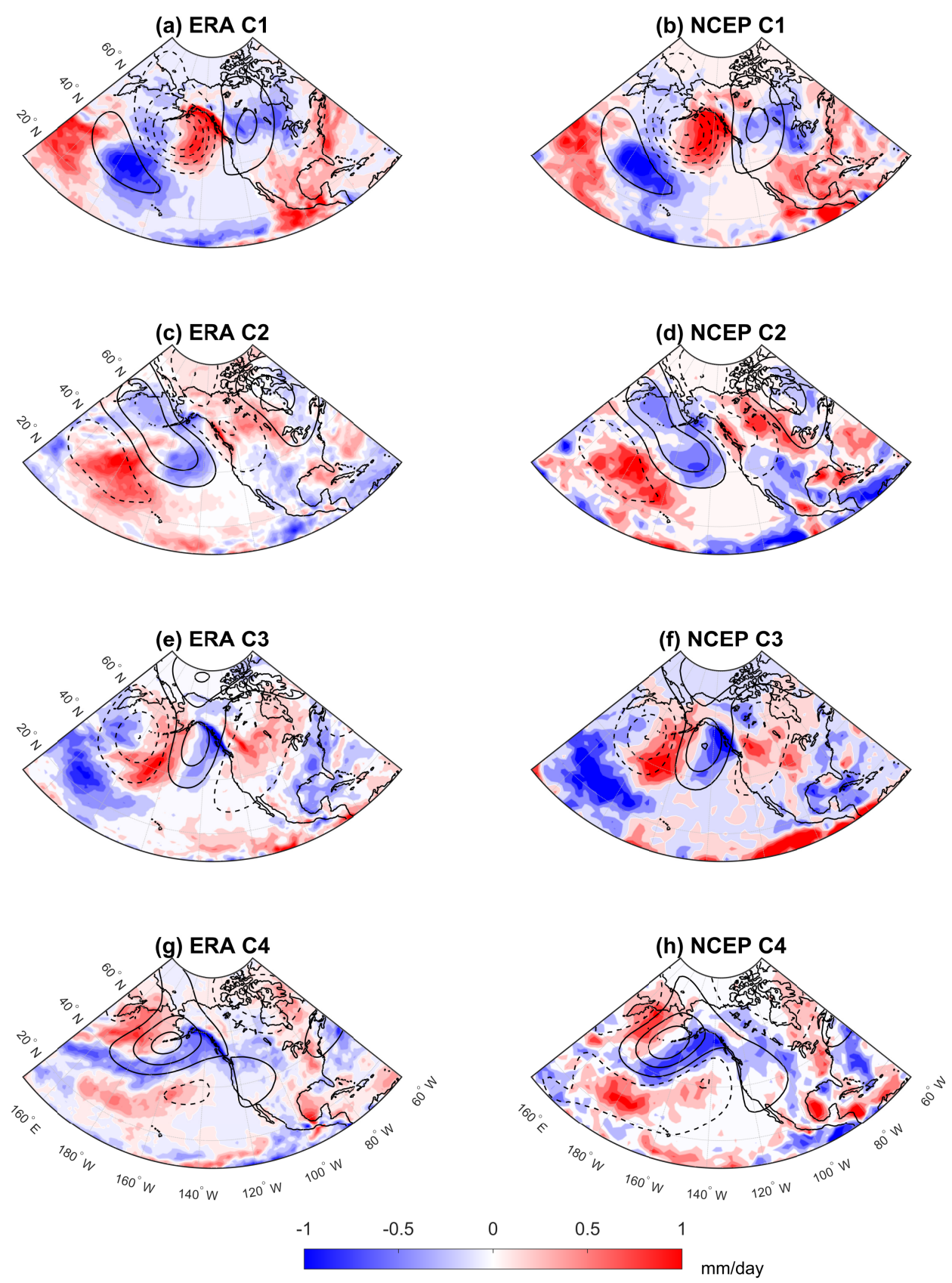

FIG. 3. Shading shows composites of precipitation rate anomalies ( $\mathrm{mm} /$ day) associated with each regime. The Left column shows the results from the ERA-Interim reanalysis (ERA), and the right column shows the results from the NCEP reanalysis. All shown anomalies are significant at the 95\% level based on a two sided Student's $t$ test. Contourlines are Z500 anomalies of cluster centers (from Fig. 1) with the interval of $20 \mathrm{~m}$.

Overall, based on the above results with the ECMWFTIGGE model, we find that the persistence and transitions of $\mathrm{C} 3$ are predicted most accurately. We also find that the persistence and transition of $\mathrm{C} 1$ and $\mathrm{C} 2$ are predicted least accurately, noting that the persistence of $\mathrm{C} 1$ is underestimated while that of $\mathrm{C} 2$ is overestimated.
A similar regime transition assessment has been carried out for the NCEP-TIGGE and GEFS models. For the NCEP-TIGGE model, Fig. 7a shows that for the forecasts initiated in $\mathrm{C} 1$, the model overestimates the persistence of the regime by $9 \%$ at day 3 , and underestimate the persistence by $8 \%$ and $4 \%$ at day 9 and 12 of the fore- 
(a) ERA

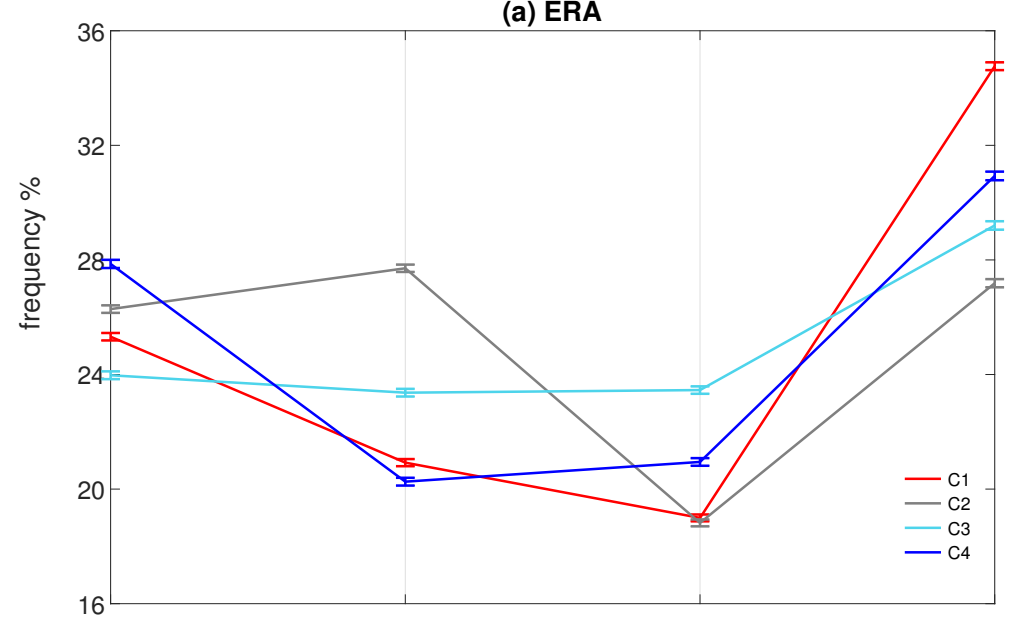

(b) NCEP

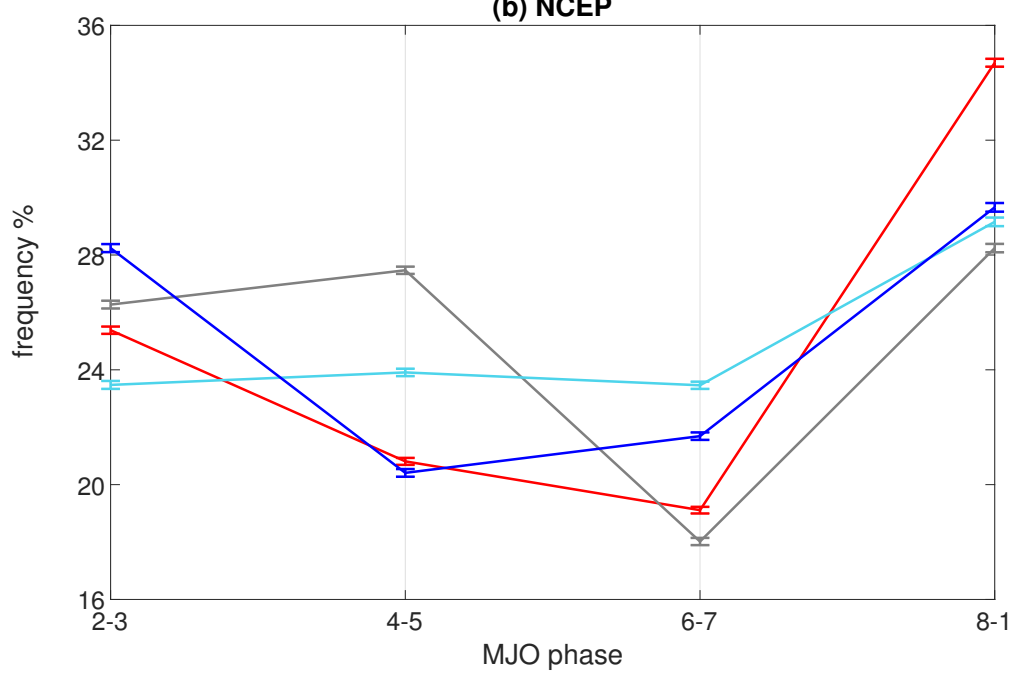

FIG. 4. Average frequency of each MJO phase-pair in the 4-10 days leading to each weather regime. (a) ERA-Interim (ERA) reanalysis, and (b) NCEP reanalysis. Uncertainties are calculated based on 1000 bootstrapped subsamples, indicating the $95 \%$ confidence intervals.

TABLE 2. Sum of the absolute differences of the predicted frequencies (all transitions and persistence) in the ECMWF-TIGGE model and the actual frequencies in the reanalysis dataset at difference forecast days. See Appendix B for more details. The uncertainty associated with each number indicates standard error among the ensemble members.

\begin{tabular}{|c|c|c|c|c|c|}
\hline initiated inlforecast day & day 3 & day 6 & day 9 & day 12 & average \\
\hline C1 & $14.3 \pm 0.1 \%$ & $9.0 \pm 0.1 \%$ & $23.6 \pm 0.1 \%$ & $23.2 \pm 0.2 \%$ & $17.5 \%$ \\
\hline C2 & $15.1 \pm 0.3 \%$ & $14.4 \pm 0.3 \%$ & $14.2 \pm 0.3 \%$ & $26.5 \pm 0.3 \%$ & $17.5 \%$ \\
\hline C 3 & $14.8 \pm 0.3 \%$ & $3.1 \pm 0.4 \%$ & $8.3 \pm 0.4 \%$ & $12.73 \pm 0.3 \%$ & $9.7 \%$ \\
\hline C4 & $7.8 \pm 0.3 \%$ & $13.5 \pm 0.5 \%$ & $13.1 \pm 0.3$ & $20.6 \pm 0.4 \%$ & $13.7 \%$ \\
\hline
\end{tabular}

cast, respectively. Transitions from $\mathrm{C} 1$ to $\mathrm{C} 4$ and $\mathrm{C} 3$ have

been accurately captured but the frequency of transition to

regime 2 is overestimated.
The forecasts initiated in C2 (Fig. 7b) and C3 (Fig. 7c) have similar persistence and regime transition trends: the persistence is overestimated throughout the prediction period, but transitions to the other regimes are predicted fairly 


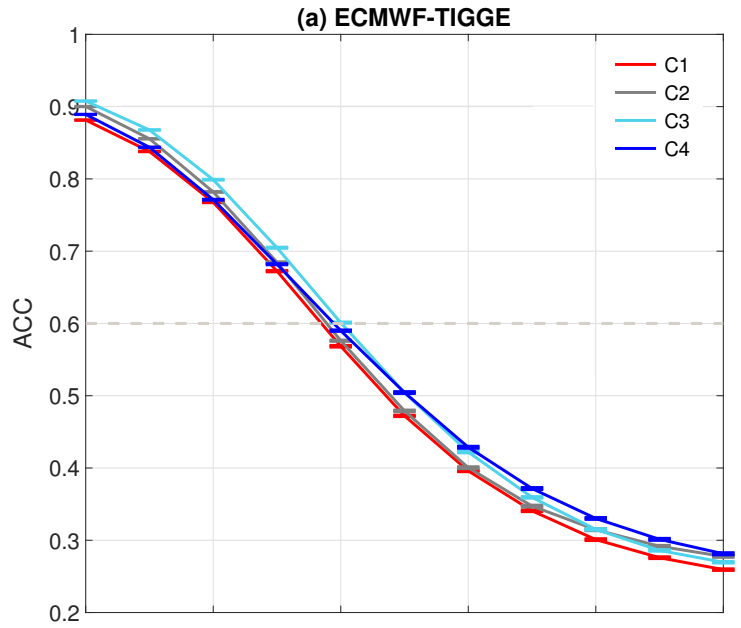

(b) NCEP-TIGGE

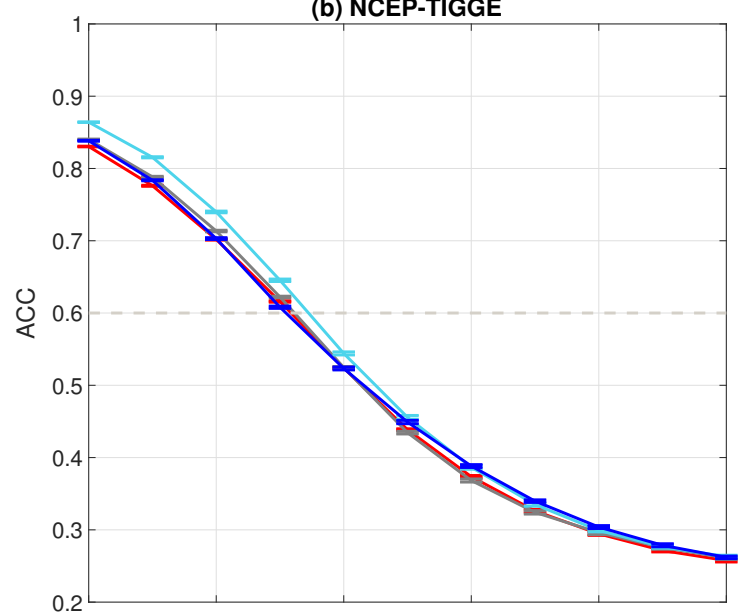

(c) GEFS

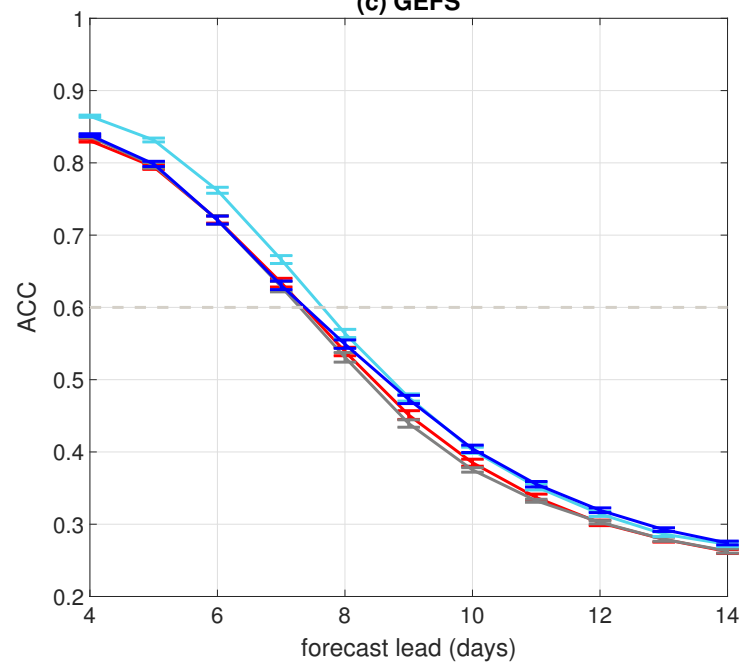

FIG. 5. Prediction skills for forecasts initiated in each weather regime presented as the ensemble-mean ACC value for each NWP model: (a) ECMWF-TIGGE, (b) NCEP-TIGGE, and (c) GEFS. The uncertainty intervals, which are small, show standard errors. 

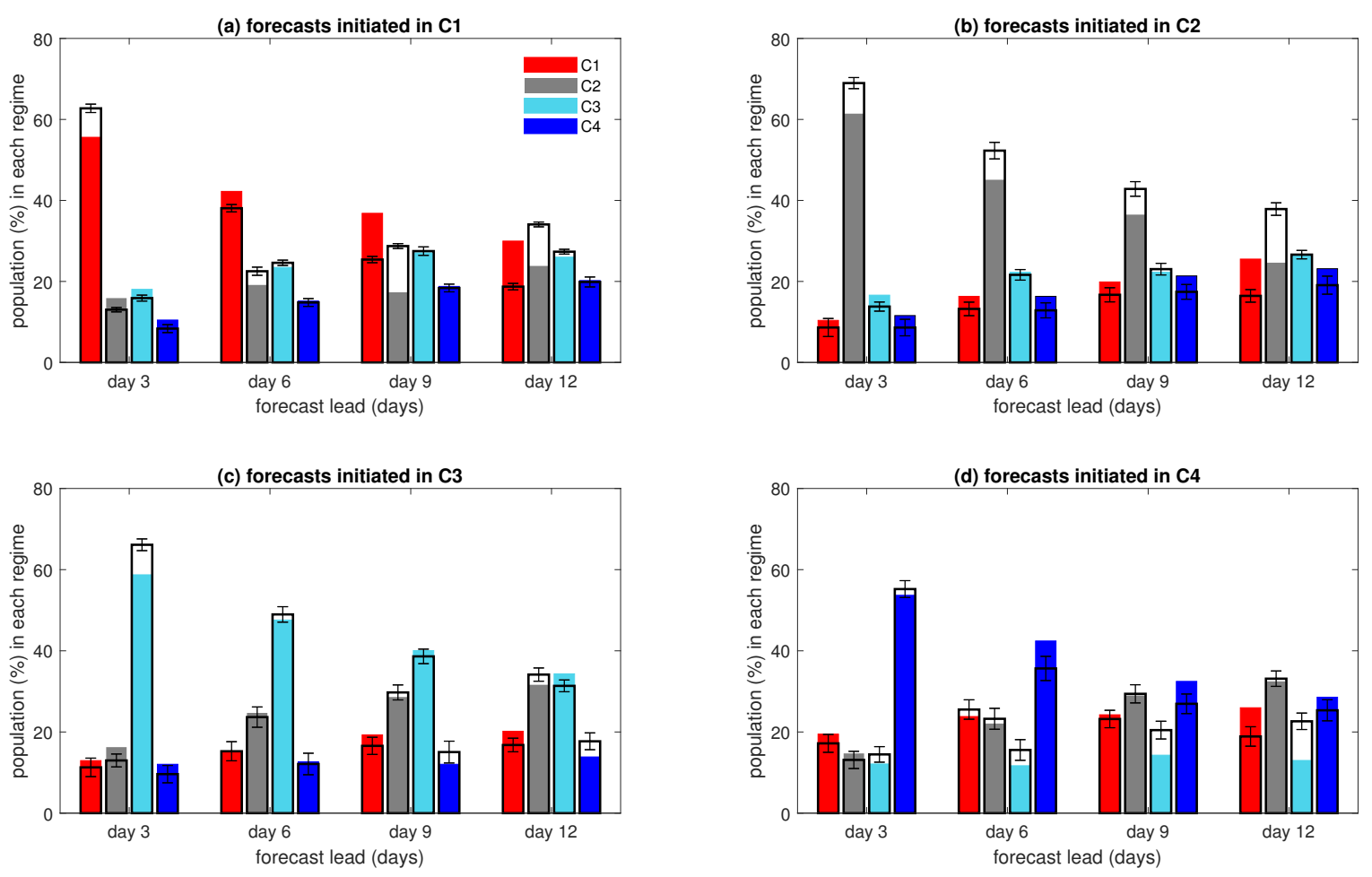

FIG. 6. The transitions among the regimes in the ECMWF-TIGGE model and ERA-Interim reanalysis dataset. Percentage of days in each regime at different forecast ranges for days initiated in (a) $\mathrm{C} 1$, (b) $\mathrm{C} 2$, (c) $\mathrm{C} 3$, and (d) C4. Color bars show the true percentages calculated from the clustering analysis of the ERA-Interim reanalysis. The black bars represent the predicted percentages. The weather regime (i.e., cluster index) of a predicted pattern is computed based on the RMSE value of the forecasted anomaly with respect to the cluster centers from reanalysis. The uncertainty intervals show the standard deviation among the ensemble members.

accurately. Similar to the ECMWF model, the absolute error for regime 3 is the lowest compared to the other regimes at forecast times longer than 3 days (Table 3 ). The persistence of regime 4 (Fig. 7d) is underestimated in this model, but the transitions to $\mathrm{C} 1$ and $\mathrm{C} 2$ have been accurately predicted. However, the model poorly forecasts the transition from $\mathrm{C} 4$ to $\mathrm{C} 3$ at longer forecast times.

In general, both TIGGE models have the highest forecast skills for C3. Common to both models, the least skillful forecasts are for $\mathrm{C} 1$. In agreement with these two models, the GEFS model underestimates the persistence of the forecasts initiated in regimes 1 (Fig. 8a) and 4 (Fig. 8d), but overestimates the persistence of the days in regimes 2 (Fig. 8b) and 3 (Fig. 8c). However, in the GEFS model, the absolute errors associated with these regimes are not always the lowest for regime 3 , as was the case for the TIGGE models. In GEFS, the trends are not robust and vary among different regimes and different forecast days (see Table 4).

Overall, based on ACC values up to day 8 (when ACC reaches around 0.6), all 3 models have the highest forecast skill for C3. Consistent between the ECMWF-TIGGE and NCEP-TIGGE models, in terms of the accuracy of the persistence and transition frequencies, the most and least skillful predictions are for $\mathrm{C} 3$ and $\mathrm{C} 1$, respectively.

\section{b. Intrinsic predictability of weather regimes}

To assess the intrinsic predictability of these regimes, we have computed the distribution of their instantaneous dimension $(d)$ and persistence $\left(\theta^{-1}\right)$. We find that for the Pacific-North American summertime circulation, the distribution of $d$ ranges from 8 to 20 , and the persistence $\left(\theta^{-1}\right)$ ranges between two to three days $\left(0.3<\theta<0.5\right.$ day $\left.^{-1}\right)$. As discussed earlier, in general, a regime with lower $d$ and $\theta$ values has higher intrinsic predictability than the one with higher $d$ and $\theta$ values (Faranda et al. 2019a; Hochman et al. 2019; Messori and Faranda 2021).

Here, we separate days with low and high values of $d$ and $\theta$ based on their mean values, which are, respectively, around 14 and $0.41 \mathrm{day}^{-1}$. Figures 9 (ERA-Interim) and 10 (NCEP) show the frequency (of days) each regime has in the lower or upper half of the $d$ and $\theta$ distributions. 

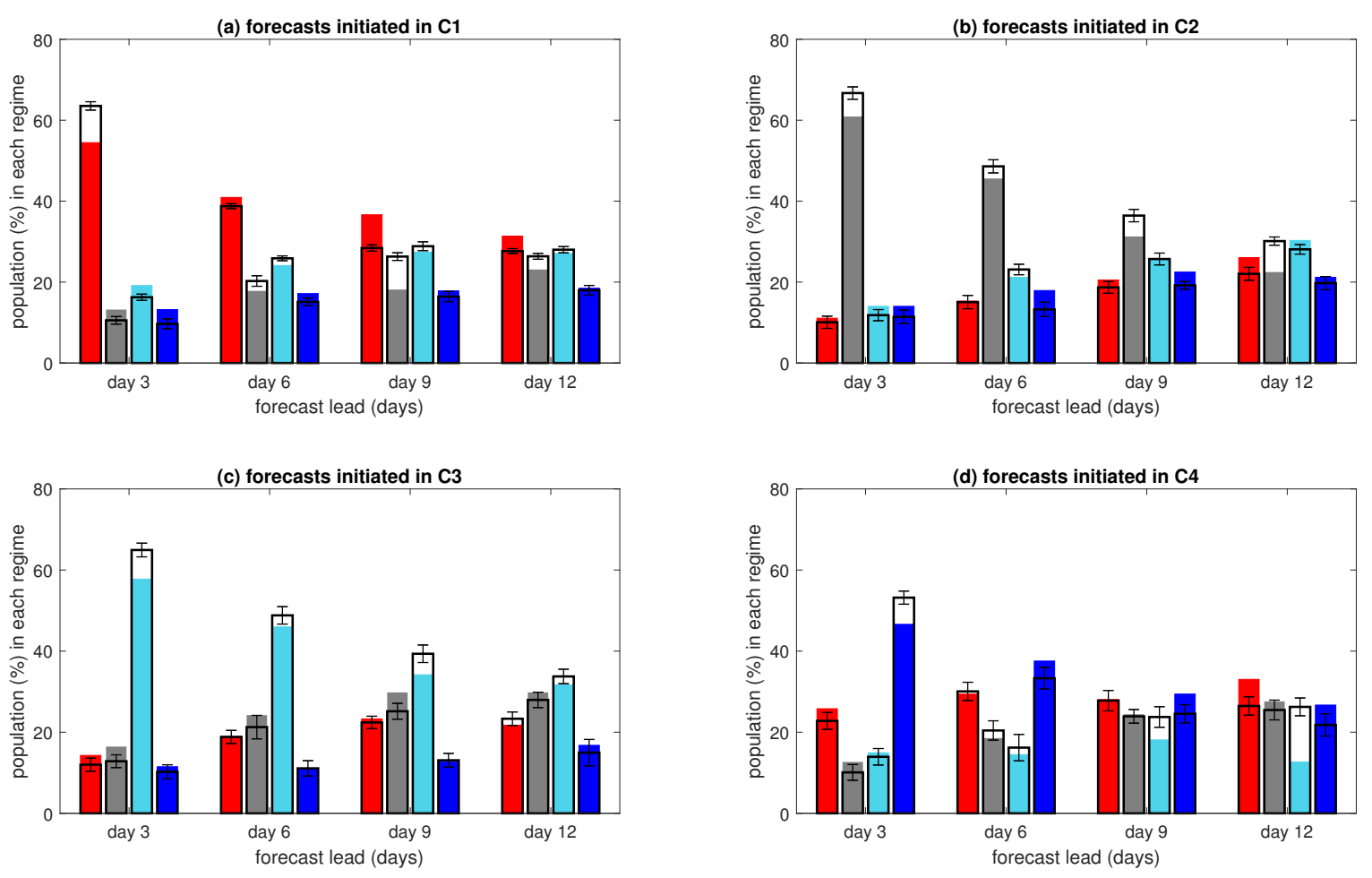

FIG. 7. The same as Fig. 6 but for the NCEP-TIGGE model and NCEP reanalysis dataset.

TABle 3. The same as Table 2 but for the NCEP-TIGGE model.

\begin{tabular}{|c|c|c|c|c|c|}
\hline initiated inlforecast day & day 3 & day 6 & day 9 & day 12 & average \\
\hline C1 & $18.1 \pm 0.3 \%$ & $8.4 \pm 0.3 \%$ & $19.2 \pm 0.3 \%$ & $18.1 \pm 0.3 \%$ & $15.9 \%$ \\
\hline C2 & $11.6 \pm 0.4 \%$ & $9.9 \pm 0.4 \%$ & $10.3 \pm 0.3 \%$ & $15.3 \pm 0.4 \%$ & $11.8 \%$ \\
\hline C3 & $14.3 \pm 0.4 \%$ & $6.1 \pm 0.7 \%$ & $11.1 \pm 0.5 \%$ & $7.3 \pm 0.7 \%$ & $9.7 \%$ \\
\hline C4 & $13.2 \pm 0.5 \%$ & $8.5 \pm 0.7 \%$ & $11.3 \pm 0.6 \%$ & $27.1 \pm 0.6$ & $15.0 \%$ \\
\hline
\end{tabular}

Consistent between the two reanalysis datasets, C3 has robustly the highest frequency among the 4 regimes in the lower half of both $d$ and $\theta$ distributions, indicating that this regime has the highest intrinsic predictability. This is fully consistent with the findings in Section $4 \mathrm{a}$, which indicated highest prediction skills for $\mathrm{C} 3$ in all 3 NWP models.

Among the four regimes, $\mathrm{C} 1$ has the highest frequency in the upper half of the $\theta$ distribution in both reanalysis datasets; however, while the differences with $\mathrm{C} 2$ and $\mathrm{C} 4$ are statistically significant, they are not large (see Figs. 9 and 10). Still, this might explain the underestimation of the persistence of $\mathrm{C} 1$ in all 3 NWP models: the highest $\theta$ value indicates the least stable regime, which leaves the current state to an existing neighborhood. Therefore, the poor forecasts of the persistence of $\mathrm{C} 1$ are likely due to a high intrinsic unpredictability. In Section 5, We will further discuss the potential implications of the low pre- dictability of this regime, which as shown in Figs. 2a-b and $3 a-b$, is associated with above-normal temperature in western North America and above-normal precipitation in the south-east United States.

Examining the distribution of $d$ values shows that $\mathrm{C} 1$ and $\mathrm{C} 4$ have comparable frequencies in the upper half (within the uncertainty range) in both reanalysis datasets (Figs. 9 and 10). Overall, the dynamical systems-based analysis clearly indicates the highest intrinsic predictability for $\mathrm{C} 3$. As for the lowest intrinsic predictability, the results are less clear, though together, $d$ and $\theta$ in both reanalysis datasets point to $\mathrm{C} 1$ as the regime with the lowest intrinsic predictability.

\section{Summary and conclusions}

In this study, we investigate the summertime weather regimes and their predictability over the Pacific-North 

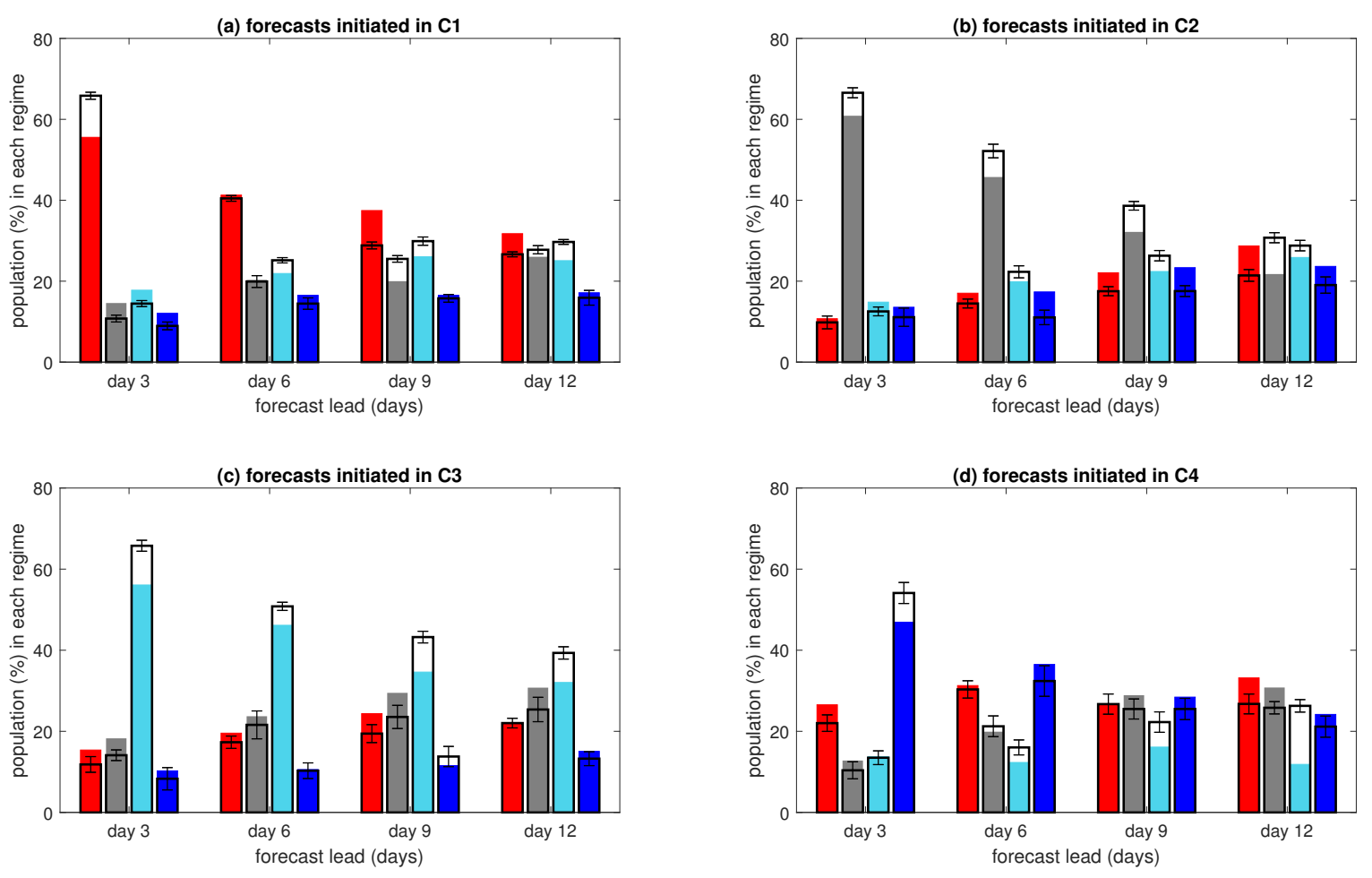

FIG. 8. The same as Fig. 6 but for the GEFS model and NCEP reanalysis dataset.

TABLE 4. The same as Table 2 but for the GEFS model.

\begin{tabular}{|c|c|c|c|c|c|}
\hline initiated inlforecast day & day 3 & day 6 & day 9 & day 12 & average \\
\hline C1 & $20.5 \pm 0.3 \%$ & $6.5 \pm 0.4 \%$ & $18.8 \pm 0.3 \%$ & $12.7 \pm 0.5 \%$ & $14.6 \%$ \\
\hline C2 & $11.4 \pm 0.7 \%$ & $17.7 \pm 0.5 \%$ & $20.7 \pm 0.4 \%$ & $23.8 \pm 0.6 \%$ & $18.4 \%$ \\
\hline C3 & $19.3 \pm 0.8 \%$ & $9.3 \pm 1 \%$ & $21.7 \pm 0.9 \%$ & $14.6 \pm 0.9 \%$ & $16.2 \%$ \\
\hline C4 & $14.4 \pm 0.8 \%$ & $10.1 \pm 1.1 \%$ & $12.7 \pm 0.8 \%$ & $28.9 \pm 0.8$ & $16.5 \%$ \\
\hline
\end{tabular}

American sector. A SOM clustering analysis is first applied to the Z500 anomalies to identify weather regimes. Four distinguishable regimes are identified corresponding to the Pacific trough (C1), Arctic low (C2), Arctic high (C3), and Alaskan ridge $(\mathrm{C} 4)$. These regimes are shown to have distinct and coherent links to surface temperature and precipitation rate anomalies over the North American continent. We also show connections between these regimes and MJO phase-pairs with 4 to 10 days time lag. These analyses together provide evidence that distinct weather regimes can be identified in the summertime Pacific-North American circulation. The distinct relationships of these regimes to the surface temperatures and precipitation anomalies suggest potentials for predictability of hot summer days or strong rainfall episodes if these regimes' evolutions and transitions can be accurately predicted. The connections to the MJO phases can further benefit regional prediction efforts (Riddle et al. 2013; Vigaud et al. 2018).

To assess the predictability of these weather regimes, we examine 4 to 14-day prediction skills of three different medium-range NWP models: ECMWF-TIGGE, NCEPTIGGE, and GEFS reforecast. Consistent among the models, based on ACC values, the most skillful forecasts, up to day 8 (when ACC reaches $\sim 0.6$ ), are those initiated in the Arctic high (C3) regime. The NWP models' ability to correctly reproduce these regimes' transitions and persistence are also examined. By separating the forecasts according to their initial conditions, we find that forecasts initiated in $\mathrm{C} 3$ have the most accurate transitions; however, models have difficulties with forecasts initiated in $\mathrm{C} 1$. The models are also found to consistently underestimate the persistence of $\mathrm{C} 1$. 


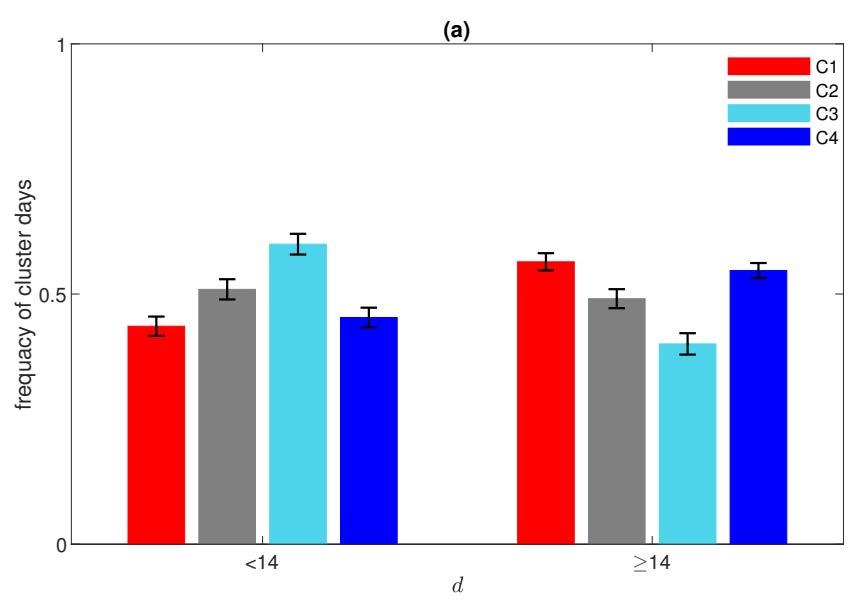

(b)

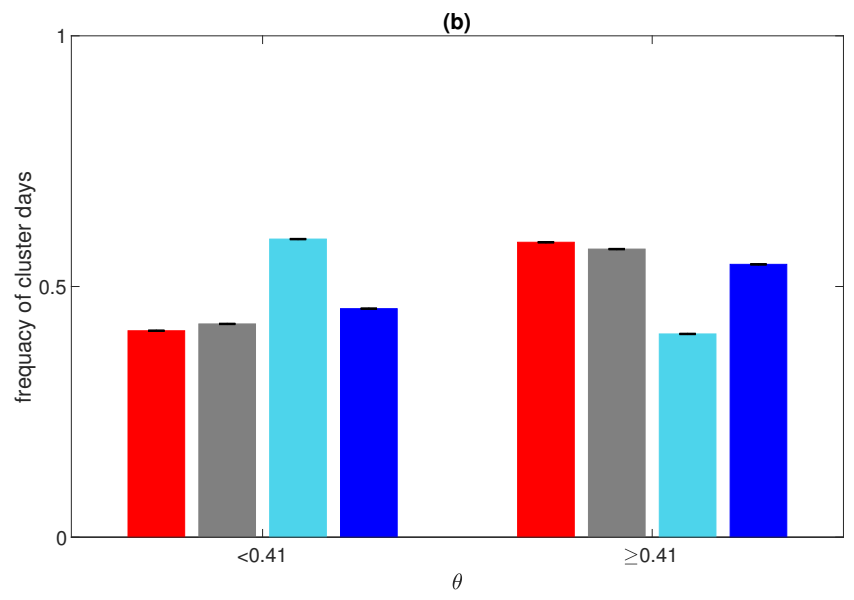

FIG. 9. Instantaneous dynamical properties of the identified weather regimes for the ERA-Interim reanalysis dataset. (a) instantaneous dimension, $d$. (b) Inverse of persistence, $\theta$ (in day ${ }^{-1}$ ). 14 and 0.41 day $^{-1}$ are the mean values of $d$ and $\theta$, respectively. Uncertainties, based on 10000 subsamples generated with bootstrapping, indicate the $95 \%$ confidence intervals. Note that the uncertainties on $\theta$ are small.

The dynamical systems-based analysis shows robustly that $\mathrm{C} 3$ has the highest intrinsic predictability among the 4 regimes, providing an explanation for the most skillful NWP forecasts for this regime. Note that the MJO North Pacific phase (phase-pairs 6-7) is the most dominant phase in the 4-10 days leading to $\mathrm{C} 3$; whether this connection to the North Pacific phase is behind the high intrinsic predictability of $\mathrm{C} 3$ should be investigated in future work.

The dynamical systems analysis (specially based on persistence) indicates that $\mathrm{C} 1$ has low intrinsic predictability. This suggests that the poor forecast skills of NWP models for this regime are likely due to high intrinsic unpredictability (rather than model errors), and might be potentially improved through better estimates of initial conditions. It is noteworthy that the $\mathrm{C} 1$ regime (Pacific trough) is associated with heat waves over western North America and above-normal rainfall around the Gulf of Mexico region. As a result, the NWP models' poor forecast skills for this regime, particularly for its persistence (which is important for extreme events), can have major socio-economic implications.

In future work, it would be interesting to examine the predictability of the weather regimes, particularly $\mathrm{C} 1$, in a warming climate. On one hand, under climate change, heat waves are expected to become stronger, longer, and larger, making the more skillful forecasts of the associated circulation patterns such as $\mathrm{C} 1$ even more important (Lau and Nath 2014; Rasmijn et al. 2018; Lyon et al. 2019; Nabizadeh et al. 2019; Perkins-Kirkpatrick and Lewis 2020; Kornhuber and Tamarin-Brodsky 2021). On the other hand, recent studies using the same dynamical systems-based analysis have shown that climate change can impact $d$ and $\theta$, thus changing the intrinsic predictability of weather regimes (Faranda et al. 2019a; Scher and Messori 2019). Therefore, the combined flow-dependent and dynamical systems-based analysis of the summertime Pacific-North American circu- 

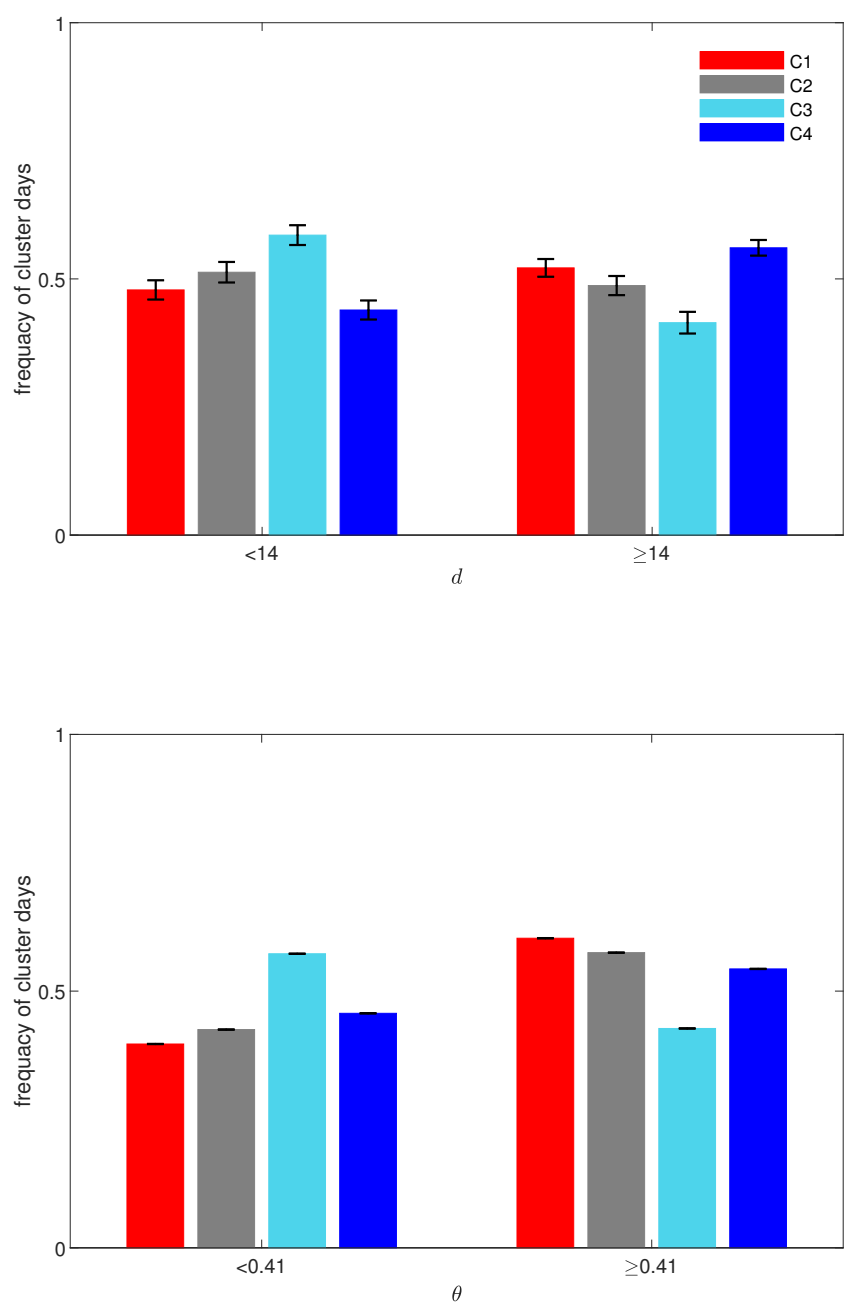

FIG. 10. The same as Fig. 9 but for the NCEP reanalysis dataset.

lation under climate change can potentially provide useful guidance for improving the forecasts of these future heat waves.

Data availability statement. The ERA-Interim and NCEP-DOE reanalysis datasets are publicly available at https://www.ecmwf.int/en/forecasts/ datasets/reanalysis-datasets/era-interim and https://www. esrl.noaa.gov/psd/data/gridded/ data.ncep.reanalysis2.html. The TIGGE and GEFS forecast datasets are freely available at https: //www. ecmwf.int/en/research/projects/tigge and https://psl.noaa.gov/forecasts/ reforecast2/download.html. Daily RMM values are available at http://www. bom.gov. au/climate/mjo/.

Acknowledgments. We thank Y. Qiang Sun for insightful discussions. This work is supported by NASA grant 80NSSC17K0266 and ONR award N00014-201-2722. Computational resources were provided by
XSEDE (allocation ATM170020), NCAR's CISL (allocation URIC0004), and Rice University Center for Research Computing.

\section{References}

Amini, S., and D. M. Straus, 2019: Control of storminess over the Pacific and North America by circulation regimes. Climate Dynamics, 52 (78), 4749-4770.

Ashok, K., M. Shamal, A. Sahai, and P. Swapna, 2017: Nonlinearities in the evolutional distinctions between El Niño and La Niña types. Journal of Geophysical Research: Oceans, 122 (12), 9649-9662.

Bao, M., and J. M. Wallace, 2015: Cluster analysis of Northern Hemisphere wintertime 500-hPa flow regimes during 1920-2014. Journal of the Atmospheric Sciences, 72 (9), 3597-3608.

Bougeault, P., and Coauthors, 2010: The THORPEX interactive grand global ensemble. Bulletin of the American Meteorological Society, 91 (8), 1059-1072. 
Brunetti, M., J. Kasparian, and C. Vérard, 2019: Co-existing climate attractors in a coupled aquaplanet. Climate Dynamics, 53 (9), 62936308 .

Buschow, S., and P. Friederichs, 2018: Local dimension and recurrent circulation patterns in long-term climate simulations. Chaos: An Interdisciplinary Journal of Nonlinear Science, 28 (8), 083124.

Camargo, S. J., M. C. Wheeler, and A. H. Sobel, 2009: Diagnosis of the MJO modulation of tropical cyclogenesis using an empirical index. Journal of the Atmospheric Sciences, 66 (10), 3061-3074.

Casola, J. H., and J. M. Wallace, 2007: Identifying weather regimes in the wintertime 500-hPa geopotential height field for the PacificNorth American sector using a limited-contour clustering technique. Journal of Applied Meteorology and Climatology, 46 (10), 16191630.

Cassou, C., 2008: Intraseasonal interaction between the Madden-Julian Oscillation and the North Atlantic Oscillation. Nature, 455 (7212), 523-527.

Chang, F.-C., and J. M. Wallace, 1987: Meteorological conditions during heat waves and droughts in the United States Great Plains. Monthly Weather Review, 115 (7), 1253-1269.

Chattopadhyay, A., P. Hassanzadeh, and S. Pasha, 2020a: Predicting clustered weather patterns: A test case for applications of convolutional neural networks to spatio-temporal climate data. Scientific Reports, 10 (1), 1-13.

Chattopadhyay, A., E. Nabizadeh, and P. Hassanzadeh, 2020b: Ana$\log$ forecasting of extreme-causing weather patterns using deep learning. Journal of Advances in Modeling Earth Systems, 12 (2), e2019MS001 958.

Dawson, A., T. Palmer, and S. Corti, 2012: Simulating regime structures in weather and climate prediction models. Geophysical Research Letters, 39 (21).

De Luca, P., G. Messori, F. M. Pons, and D. Faranda, 2020: Dynamical systems theory sheds new light on compound climate extremes in Europe and Eastern North America. Quarterly Journal of the Royal Meteorological Society, 146 (729), 1636-1650.

Dee, D. P., and Coauthors, 2011: The ERA-Interim reanalysis: Configuration and performance of the data assimilation system. Quarterly Journal of the Royal Meteorological Society, 137 (656), 553-597.

Fabiano, F., V. L. Meccia, P. Davini, P. Ghinassi, and S. Corti, 2021: A regime view of future atmospheric circulation changes in northern mid-latitudes. Weather and Climate Dynamics, 2 (1), 163-180.

Falkena, S. K., J. de Wiljes, A. Weisheimer, and T. G. Shepherd, 2020: Revisiting the identification of wintertime atmospheric circulation regimes in the Euro-Atlantic sector. Quarterly Journal of the Royal Meteorological Society, 146 (731), 2801-2814.

Faranda, D., M. C. Alvarez-Castro, G. Messori, D. Rodrigues, and P. Yiou, 2019a: The hammam effect or how a warm ocean enhances large scale atmospheric predictability. Nature Communications, 10 (1), 1-7.

Faranda, D., G. Masato, N. Moloney, Y. Sato, F. Daviaud, B. Dubrulle, and P. Yiou, 2016: The switching between zonal and blocked midlatitude atmospheric circulation: a dynamical system perspective. Climate Dynamics, 47 (5), 1587-1599.

Faranda, D., G. Messori, M. C. Alvarez-Castro, and P. Yiou, 2017a: Dynamical properties and extremes of Northern Hemisphere climate fields over the past 60 years. Nonlinear Processes in Geophysics, 24 (4), 713-725.

Faranda, D., G. Messori, and S. Vannitsem, 2019b: Attractor dimension of time-averaged climate observables: insights from a loworder ocean-atmosphere model. Tellus A: Dynamic Meteorology and Oceanography, 71 (1), 1554413.

Faranda, D., G. Messori, and P. Yiou, 2017b: Dynamical proxies of North Atlantic predictability and extremes. Scientific Reports, 7, 41278.

Ferranti, L., S. Corti, and M. Janousek, 2015: Flow-dependent verification of the ECMWF ensemble over the Euro-Atlantic sector. Quarterly Journal of the Royal Meteorological Society, 141 (688), 916-924.

Ferranti, L., L. Magnusson, F. Vitart, and D. S. Richardson, 2018: How far in advance can we predict changes in large-scale flow leading to severe cold conditions over Europe? Quarterly Journal of the Royal Meteorological Society, 144 (715), 1788-1802.

Freitas, A. C. M., J. M. Freitas, and M. Todd, 2010: Hitting time statistics and extreme value theory. Probability Theory and Related Fields, 147 (3-4), 675-710.

Gervais, M., J. Shaman, and Y. Kushnir, 2020: Impact of the North Atlantic warming hole on sensible weather. Journal of Climate, $\mathbf{3 3}(\mathbf{1 0})$, 4255-4271.

Ghil, M., and A. W. Robertson, 2002: hă̌IJwavesâĂİ vs.âĂIJparticlesâĂİ in the atmosphere's phase space: A pathway to long-range forecasting? Proceedings of the National Academy of Sciences, 99 (suppl 1), 2493-2500.

Gibson, P. B., D. E. Waliser, B. Guan, M. J. DeFlorio, F. M. Ralph, and D. L. Swain, 2020: Ridging associated with drought across the western and southwestern United States: Characteristics, trends, and predictability sources. Journal of Climate, 33 (7), 2485-2508.

Hamill, T. M., G. T. Bates, J. S. Whitaker, D. R. Murray, M. Fiorino, T. J. Galarneau Jr, Y. Zhu, and W. Lapenta, 2013: NOAA's secondgeneration global medium-range ensemble reforecast dataset. Bulletin of the American Meteorological Society, 94 (10), 1553-1565.

Hannachi, A., and W. Iqbal, 2019: On the nonlinearity of winter Northern Hemisphere atmospheric variability. Journal of the Atmospheric Sciences, 76 (1), 333-356.

Hassanzadeh, P., C.-Y. Lee, E. Nabizadeh, S. J. Camargo, D. Ma, and L. Y. Yeung, 2020: Effects of climate change on the movement of future landfalling Texas tropical cyclones. Nature Communications, $11(1), 1-9$.

Hochman, A., P. Alpert, T. Harpaz, H. Saaroni, and G. Messori, 2019: A new dynamical systems perspective on atmospheric predictability: Eastern mediterranean weather regimes as a case study. Science advances, 5 (6), eaau0936.

Horton, D. E., N. C. Johnson, D. Singh, D. L. Swain, B. Rajaratnam, and N. S. Diffenbaugh, 2015: Contribution of changes in atmospheric circulation patterns to extreme temperature trends. Nature, 522 (7557), 465-469.

Johnson, N. C., and S. B. Feldstein, 2010: The continuum of North Pacific sea level pressure patterns: Intraseasonal, interannual, and interdecadal variability. Journal of Climate, 23 (4), 851-867.

Johnson, N. C., S. B. Feldstein, and B. Tremblay, 2008: The continuum of Northern Hemisphere teleconnection patterns and a description 
of the NAO shift with the use of self-organizing maps. Journal of Climate, 21 (23), 6354-6371.

Kanamitsu, M., W. Ebisuzaki, J. Woollen, S.-K. Yang, J. Hnilo, M. Fiorino, and G. Potter, 2002: NCEP-DOE AMIP-ii reanalysis (r-2). Bulletin of the American Meteorological Society, 83 (11), 1631-1644.

Kohonen, T., 2012: Self-organizing maps, Vol. 30. Springer Science \& Business Media.

Kornhuber, K., and T. Tamarin-Brodsky, 2021: Future changes in Northern Hemisphere summer weather persistence linked to projected Arctic warming. Geophysical Research Letters, 48 (4), e2020GL091 603.

Kossin, J. P., S. J. Camargo, and M. Sitkowski, 2010: Climate modulation of North Atlantic hurricane tracks. Journal of Climate, 23 (11), 3057-3076.

Lau, N.-C., and M. J. Nath, 2014: Model simulation and projection of European heat waves in present-day and future climates. Journal of Climate, 27 (10), 3713-3730.

Lee, S., and S. B. Feldstein, 2013: Detecting ozone-and greenhouse gas-driven wind trends with observational data. Science, 339 (6119), 563-567.

Lee, Y.-Y., and R. Grotjahn, 2019: Evidence of specific MJO phase occurrence with summertime california central valley extreme hot weather. Advances in Atmospheric Sciences, 36 (6), 589-602.

L'Heureux, M. L., and R. W. Higgins, 2008: Boreal winter links between the Madden-Julian Oscillation and the Arctic Oscillation. Journal of Climate, 21 (12), 3040-3050.

Lorenz, E. N., 1996: Predictability: A problem partly solved. Predictability of Weather and Climate, Vol. 1.

Lucarini, V., D. Faranda, and J. Wouters, 2012: Universal behaviour of extreme value statistics for selected observables of dynamical systems. Journal of Statistical Physics, 147 (1), 63-73.

Lucarini, V., and Coauthors, 2016: Extremes and recurrence in dynamical systems. John Wiley \& Sons.

Lyon, B., A. G. Barnston, E. Coffel, and R. M. Horton, 2019: Projected increase in the spatial extent of contiguous US summer heat waves and associated attributes. Environmental Research Letters, 14 (11), 114029 .

Matsueda, M., and T. Palmer, 2018: Estimates of flow-dependent predictability of wintertime Euro-Atlantic weather regimes in mediumrange forecasts. Quarterly Journal of the Royal Meteorological Society, 144 (713), 1012-1027.

Messori, G., R. Caballero, and D. Faranda, 2017: A dynamical systems approach to studying midlatitude weather extremes. Geophysical Research Letters, 44 (7), 3346-3354.

Messori, G., and D. Faranda, 2021: Characterising and comparing different palaeoclimates with dynamical systems theory. Climate of the Past, 17 (1), 545-563.

Messori, G., and Coauthors, 2018: An interdisciplinary approach to the study of extreme weather events: large-scale atmospheric controls and insights from dynamical systems theory and statistical mechanics. Bulletin of the American Meteorological Society, 99 (5), ES81-ES85.

Michel, C., and G. Rivière, 2011: The link between Rossby wave breakings and weather regime transitions. Journal of the Atmospheric Sciences, 68 (8), 1730-1748.
Michelangeli, P.-A., R. Vautard, and B. Legras, 1995: Weather regimes: Recurrence and quasi stationarity. Journal of the Atmospheric Sciences, 52 (8), 1237-1256.

Mo, K., and M. Ghil, 1988: Cluster analysis of multiple planetary flow regimes. Journal of Geophysical Research: Atmospheres, 93 (D9), $10927-10952$.

Nabizadeh, E., P. Hassanzadeh, D. Yang, and E. A. Barnes, 2019: Size of the atmospheric blocking events: Scaling law and response to climate change. Geophysical Research Letters, 46 (22), 13 488-13 499.

Pasquier, J., S. Pfahl, and C. M. Grams, 2019: Modulation of atmospheric river occurrence and associated precipitation extremes in the North Atlantic region by European weather regimes. Geophysical Research Letters, 46 (2), 1014-1023.

Perkins-Kirkpatrick, S., and S. Lewis, 2020: Increasing trends in regional heatwaves. Nature Communications, 11 (1), 1-8.

Rasmijn, L., G. Van der Schrier, R. Bintanja, J. Barkmeijer, A. Sterl, and W. Hazeleger, 2018: Future equivalent of 2010 Russian heatwave intensified by weakening soil moisture constraints. Nature Climate Change, 8 (5), 381-385.

Riddle, E. E., M. B. Stoner, N. C. Johnson, M. L. LHeureux, D. C. Collins, and S. B. Feldstein, 2013: The impact of the MJO on clusters of wintertime circulation anomalies over the North American region. Climate Dynamics, 40 (7-8), 1749-1766.

Robertson, A. W., and M. Ghil, 1999: Large-scale weather regimes and local climate over the western United States. Journal of Climate, 12 (6), 1796-1813.

Robertson, A. W., Y. Kushnir, U. Lall, and J. Nakamura, 2015: Weather and climatic drivers of extreme flooding events over the midwest of the United States. Extreme Events: Observations, Modeling, and Economics, 113-124.

Robertson, A. W., and C. R. Mechoso, 2003: Circulation regimes and low-frequency oscillations in the south pacific sector. Monthly Weather Review, 131 (8), 1566-1576.

Robertson, A. W., N. Vigaud, J. Yuan, and M. K. Tippett, 2020: Toward identifying subseasonal forecasts of opportunity using North American weather regimes. Monthly Weather Review, 148 (5), 1861-1875.

Robin, Y., P. Yiou, and P. Naveau, 2017: Detecting changes in forced climate attractors with Wasserstein distance. Nonlinear Processes in Geophysics, 24 (3), 393-405.

Rodrigues, D., M. C. Alvarez-Castro, G. Messori, P. Yiou, Y. Robin, and D. Faranda, 2018: Dynamical properties of the North Atlantic atmospheric circulation in the past 150 years in CMIP5 models and the 20CRv2c reanalysis. Journal of Climate, 31 (15), 6097-6111.

Sahai, A., N. Borah, R. Chattopadhyay, S. Joseph, and S. Abhilash, 2017: A bias-correction and downscaling technique for operational extended range forecasts based on self organizing map. Climate Dynamics, 48 (7-8), 2437-2451.

Scher, S., and G. Messori, 2019: How global warming changes the difficulty of synoptic weather forecasting. Geophysical Research Letters, 46 (5), 2931-2939.

Schreck, C. J., J. M. Cordeira, and D. Margolin, 2013: Which MJO events affect North American temperatures? Monthly Weather Review, 141 (11), 3840-3850. 
Singh, D., D. L. Swain, J. S. Mankin, D. E. Horton, L. N. Thomas, B. Rajaratnam, and N. S. Diffenbaugh, 2016: Recent amplification of the North American winter temperature dipole. Journal of Geophysical Research: Atmospheres, 121 (17), 9911-9928.

Stan, C., and D. M. Straus, 2007: Is blocking a circulation regime? Monthly Weather Review, 135 (6), 2406-2413.

Straus, D. M., 2018: Clustering techniques in climate analysis. Oxford Research Encyclopedia of Climate Science.

Straus, D. M., S. Corti, and F. Molteni, 2007: Circulation regimes: Chaotic variability versus SST-forced predictability. Journal of Climate, 20 (10), 2251-2272.

Straus, D. M., and F. Molteni, 2004: Circulation regimes and SST forcing: Results from large GCM ensembles. Journal of Climate, 17 (8), 1641-1656.

Strommen, K., and T. N. Palmer, 2019: Signal and noise in regime systems: A hypothesis on the predictability of the North Atlantic Oscillation. Quarterly Journal of the Royal Meteorological Society, 145 (718), 147-163.

Swinbank, R., and Coauthors, 2016: The TIGGE project and its achievements. Bulletin of the American Meteorological Society, 97 (1), 4967.

van der Wiel, K., H. C. Bloomfield, R. W. Lee, L. P. Stoop, R. Blackport, J. A. Screen, and F. M. Selten, 2019: The influence of weather regimes on European renewable energy production and demand. Environmental Research Letters, 14 (9), 094010.

Vautard, R., 1990: Multiple weather regimes over the North Atlantic: Analysis of precursors and successors. Monthly Weather Review, 118 (10), 2056-2081.

Vavrus, S. J., F. Wang, J. E. Martin, J. A. Francis, Y. Peings, and J. Cattiaux, 2017: Changes in North American atmospheric circulation and extreme weather: Influence of Arctic amplification and Northern Hemisphere snow cover. Journal of Climate, 30 (11), 4317-4333.

Vigaud, N., A. W. Robertson, and M. K. Tippett, 2017: Multimodel ensembling of subseasonal precipitation forecasts over North America. Monthly Weather Review, 145 (10), 3913-3928.

Vigaud, N., A. W. Robertson, and M. K. Tippett, 2018: Predictability of recurrent weather regimes over North America during winter from submonthly reforecasts. Monthly Weather Review, 146 (8), 25592577.

Vigaud, N., M. K. Tippett, J. Yuan, A. W. Robertson, and N. Acharya, 2019: Probabilistic skill of subseasonal surface temperature forecasts over North America. Weather and Forecasting, 34 (6), 1789-1806.

Vitart, F., 2009: Impact of the Madden Julian Oscillation on tropical storms and risk of landfall in the ECMWF forecast system. Geophysical Research Letters, 36 (15).

Vitart, F., and Coauthors, 2017: The subseasonal to seasonal (S2S) prediction project database. Bulletin of the American Meteorological Society, 98 (1), 163-173.

Weisheimer, A., D. Decremer, D. MacLeod, C. O’Reilly, T. N. Stockdale, S. Johnson, and T. N. Palmer, 2019: How confident are predictability estimates of the winter North Atlantic Oscillation? Quarterly Journal of the Royal Meteorological Society, 145, 140-159.
Wheeler, M. C., and H. H. Hendon, 2004: An all-season real-time multivariate MJO index: Development of an index for monitoring and prediction. Monthly Weather Review, 132 (8), 1917-1932.

Woollings, T., A. Hannachi, and B. Hoskins, 2010: Variability of the North Atlantic eddy-driven jet stream. Quarterly Journal of the Royal Meteorological Society, 136 (649), 856-868.

Yiou, P., K. Goubanova, Z. Li, and M. Nogaj, 2008: Weather regime dependence of extreme value statistics for summer temperature and precipitation. Nonlinear Processes in Geophysics, 15 (3), 365-378.

Zhang, C., 2013: Madden-Julian Oscillation: Bridging weather and climate. Bulletin of the American Meteorological Society, 94 (12), 1849-1870.

Zheng, J., and C. Wang, 2019: Hot summers in the Northern Hemisphere. Geophysical Research Letters, 46 (19), 10 891-10 900.

\section{APPENDIX A}

\section{Calculation of local dimension and persistence: More details}

Calculations of $d$ and $\theta$ follow the steps described in Lucarini et al. (2016), Messori et al. (2017), and Faranda et al. (2017b). Briefly, for a given state of interest $\xi$ (which is a chosen daily Z500 pattern), we first use the distance calculated in Eq. (3) to define an observable via logarithmic operant

$$
g(Z(t), \xi)=-\log (\operatorname{dist}(Z(t), \xi)) .
$$

Following Messori et al. (2017), observables with values above the $q=0.98$ percentile of $g$ (defined as $g^{98 t h}$ ) are retained and then the $g^{98 t h}$ is used as a threshold to compute consecutive exceedances (recurrences) $E$ as

$$
\begin{gathered}
E(Z(t), \xi)=g(Z(t), \xi)-g^{98 t h}, \\
\forall g(Z(t), \xi)>g^{98 t h} .
\end{gathered}
$$

Finally, we use $E(Z(t), \xi)$ to calculate the local dimension $d$ of $\xi$ as

$$
d(\xi)=1 / \text { mean }(E) .
$$

Using the same value of percentile $(q=0.98)$, the inverse of persistence for $\xi$ is computed as (Messori et al. 2017)

$$
\begin{aligned}
& \theta(\xi)=\frac{\sum_{i}^{N_{c}}(1-q) S_{i}+N+N_{c}}{2 \sum_{i}^{N_{c}}(1-q) S_{i}}- \\
& \frac{\sqrt{\left(\sum_{i}^{N_{c}}(1-q) S_{i}+N+N_{c}\right)^{2}-8 N_{c} \sum_{i}^{N_{c}}(1-q) S_{i}}}{2 \sum_{i}^{N_{c}}(1-q) S_{i}}
\end{aligned}
$$

where $N$ is the number of total recurrences above the chosen threshold, $q=0.98 . N_{c}$ is the number of observations that fall above $q$ for at least two consecutive days, and form a subset with a length of $S_{i}$. 


\section{APPENDIX B}

\section{Forecast errors of transitions}

To compare the overall forecast errors associated with days initiated in each regime, sum of the absolute differences of the predicted frequencies (all transitions and persistence) for each model is calculated as

$$
\epsilon(i, f)=\sum_{r=1}^{4}\left|F_{r}(i)-T_{r}(i)\right|,
$$

where $\epsilon$ is the total forecast error for days initiated in regime $i$ at a given forecast day $f$. Here, $r$ is the cluster index for each regime. $F_{r}(i)$ and $T_{r}(i)$ are the forecasted and true frequencies of cluster $r$ for days initiated in regime $i$. Values of $\epsilon$ for the ECMWF-TIGGE, NCEP-TIGGE, and GEFS models for $f=3,6,9$, and 12 days are presented in Tables 2,3 , and 4 , respectively. 